\title{
Enhanced detection sensitivity of Escherichia coli OI57:H7 using surface-modified gold nanorods
}

\author{
This article was published in the following Dove Press journal: \\ International Journal of Nanomedicine \\ 27 August 2015 \\ Number of times this article has been viewed
}

\author{
Mohankandhasamy \\ Ramasamy' \\ Dong Kee $\mathrm{Yi}^{2,3}$ \\ Seong Soo A An ${ }^{4}$ \\ 'School of Chemical Engineering, \\ Yeungnam University, Gyeongsan, \\ ${ }^{2}$ Department of Chemistry, \\ ${ }^{3}$ Department of Energy and \\ Biotechnology, Myongji University, \\ Yongin, ${ }^{4}$ Department of BioNano \\ Technology, Gachon University, \\ Seongnam, Republic of Korea
}

Correspondence: Seong Soo A An Department of BioNano Technology, Gachon University, I 342 Seongnamdaero, Sujeong-gu, Seongnam, Gyeonggi-do 46I 70I, Republic of Korea

$\mathrm{Tel}+8231750$ 898I

Email seongaan@gachon.ac.kr

Dong Kee Yi

Department of Chemistry, Myongji

University, II 6 Myongji-ro, Cheoin-gu,

Yongin, Gyeonggi-do 449 728,

Republic of Korea

$\mathrm{Tel}+82313306178$

Email vitalis@mju.ac.kr
Abstract: Escherichia coli $\mathrm{O} 157: \mathrm{H} 7$ (O157) is a Gram negative and highly virulent bacteria found in food and water sources, and is a leading cause of chronic diseases worldwide. Diagnosis and prevention from the infection require simple and rapid analysis methods for the detection of pathogens, including O157. Endogenous membrane peroxidase, an enzyme present on the surface of $\mathrm{O} 157$, was used for the colorimetric detection of bacteria by catalytic oxidation of the peroxidase substrate. In this study, we have analyzed the impact of the synthesized bare gold nanorods (AuNRs) and silica-coated AuNRs on the growth of E. coli O157. Along with the membrane peroxidase activity of O157, other bacteria strains were analyzed. Different concentrations of nanorods were used to analyze the growth responses, enzymatic changes, and morphological alterations of bacteria by measuring optical density, 3,3',5,5'-tetramethylbenzidine assay, flow cytometry analysis, and microscopy studies. The results revealed that $\mathrm{O} 157$ showed higher and continuous membrane peroxidase activity than other bacteria. Furthermore, O157 treated with bare AuNRs showed a decreased growth rate in comparison with the bacteria with surface modified AuNRs. Interestingly, silica-coated AuNRs favored the growth of bacteria and also increased membrane peroxidase activity. This result can be particularly important for the enzymatic analysis of surface treated AuNRs in various microbiological applicants.

Keywords: E. coli, O157:H7, endogenous membrane peroxidase, gold nanorod, silica-coated gold nanorod

\section{Introduction}

Consumption of microbial-contaminated food or water is still one of the main causes of death in this 21 st century. ${ }^{1}$ According to the report of the World Health Organization, approximately two million people died in 2005 because of consumption of microbialcontaminated food or water. The common pathogenic strain that released potent toxins and was responsible for complex food-borne diseases was Escherichia coli O157:H7 (O157). E. coli $\mathrm{O} 157$ is a serotype, Gram-negative, highly virulent anthropozoonosic pathogen found in contaminated water, and foods like uncooked beef, unpasteurized milk, juice, and salami. This pathogen spreads from animals and could be fatal to humans. ${ }^{2,3}$ O157 strain causes life-threatening diseases such as hemolytic uremic syndrome (HUS), hemorrhagic colitis, renal failure, central nervous system failure, and even death. ${ }^{4}$ For treatment, antibiotics are given with caution since they produce kidney complications leading to HUS. ${ }^{5}$ Antidiarrheal agents reduce the bowel activity that leads to delayed antibacterial action on $\mathrm{O} 157$ which allow them to proliferate highly in the digestive tract. Antispasmodic drugs with analgesics are commonly prescribed for suppressing COX-2-dependent prostaglandins synthesis. ${ }^{6}$

O157 bacteria carry proteins, receptors, and enzymes on their surfaces, especially heme-binding enzyme catalase-peroxidases or membrane peroxidases, which are believed to be involved in the bacterial defense mechanisms against oxidative stresses. ${ }^{7}$ 
Eukaryotic enzymes like endogenous membrane peroxidase have potential applications and are used as markers for monitoring the enzymatic activity in bacterial cells. Conventional methods used to detect bacteria include colony counting, immunology-based enzyme-linked immunosorbent assays, and polymerase chain reaction, which are time consuming and require special sample pretreatment. ${ }^{8-10}$ Biosensor-based detection techniques are sensitive, specific, and reliable, however, they require special chemical and fluidic attachments such as antibodies. ${ }^{11}$

Emerging trends in nanotechnology open up materials to be applied in various aspects of biomedical applications, including antimicrobes, ${ }^{12}$ cancer imaging and therapy, ${ }^{13,14}$ drug or DNA delivery, ${ }^{15,16}$ enzyme sensors, ${ }^{17} \mathrm{UV}$ protector, ${ }^{18}$ and so forth.Au@Pt nanomaterials with hydrogen peroxide $\left(\mathrm{H}_{2} \mathrm{O}_{2}\right)$ have been reported as peroxidase mimetic in immunoassays and glucose sensing. ${ }^{19,20}$ Several studies have reported the intrinsic peroxidase mimicking activity of nanostructured materials that can be used in traditional enzyme-linked immunosorbent assay method after replacing horseradish peroxidase with $\mathrm{CeO}_{2}, \mathrm{Pt}$, carbon, and magnetic nanoparticles. ${ }^{21-24}$ Gold nanostructures have recently been useful in bio-applications because of their nontoxicity, ease of surface modification, polyvalent effects, and photothermal capacity. ${ }^{25-27}$ Zhao et $\mathrm{al}^{28}$ and Ma et $\mathrm{al}^{29}$ developed organic molecule-attached gold nanoparticles for bacteria lyses through cell membrane rupture, attachment with nucleic acids, and inhibition of protein synthesis. There are no existing reports that explain the interaction of metal nanostructures with $E$. coli $\mathrm{O} 157$ and its enzymatic activity without $\mathrm{H}_{2} \mathrm{O}_{2}$.

Herein, we have analyzed the membrane peroxidase activity of E. coli O157, Enterococcus faecalis, Bacillus subtilis, and Salmonella typhi. And their continuous enzyme activity was compared. Then, the growth of $E$. coli $\mathrm{O} 157$ was assessed against the prepared bare gold nanorods (AuNRs) and silica-coated AuNRs (Si-AuNRs). Further, alterations in enzymatic activity of $E$. coli $\mathrm{O} 157$ in the presence of synthesized nanorods were studied. Finally, the morphological changes of bacteria before and after treatment with different nanorods were examined.

\section{Materials and methods Materials}

Ready-made phosphate-buffered saline (PBS) solution, Lysogeny Broth (LB) broth (BD Biosciences, San Jose, CA, USA), and 3,3',5,5'-tetramethylbenzidine (TMB) were purchased from Sigma-Aldrich (St Louis, MO, USA). Cetyltrimethylammonium bromide (CTAB), 3-mercaptopropyl trimethoxysilane (MPTMS), 3-aminopropyldimethyl-ethoxy silane (APDES), ammonium hydroxide $\left(\mathrm{NH}_{4} \mathrm{OH} ; 28 \mathrm{wt} \%\right.$ in water), silver nitrate $\left(\mathrm{AgNO}_{3}\right)$, sodium borohydride $\left(\mathrm{NaBH}_{4}\right)$, ascorbic acid, ethanol, hydrogen tetrachloroaurate(III) trihydrate $\left(\mathrm{HAuCl}_{4} \cdot 3 \mathrm{H}_{2} \mathrm{O}\right)$, methanol, and sulfuric acid $\left(\mathrm{H}_{2} \mathrm{SO}_{4}\right)$ were purchased from Sigma-Aldrich.

\section{Preparation of AuNRs}

AuNRs were prepared by modified seed-mediated method described elsewhere. ${ }^{30}$ In brief, $250 \mu \mathrm{L}$ of $0.01 \mathrm{M} \mathrm{HAuCl}_{4}$ was mixed with $7.5 \mathrm{~mL}$ of $0.1 \mathrm{M} \mathrm{CTAB}$ and $600 \mu \mathrm{L}$ of ice-cold $0.01 \mathrm{M} \mathrm{NaBH}_{4}$ under vigorous stirring at room temperature to make seed solution. Next, the growth solution was prepared by adding $400 \mu \mathrm{L}$ of $0.01 \mathrm{M} \mathrm{HAuCl}_{4}, 64 \mu \mathrm{L}$ of $0.1 \mathrm{M}$ ascorbic acid, and $35.6 \mu \mathrm{L}$ of $0.1 \mathrm{M} \mathrm{AgNO}_{3}$ in $9.5 \mathrm{~mL}$ of $0.1 \mathrm{M} \mathrm{CTAB}$. Finally, $10 \mu \mathrm{L}$ of 2.5 -hour-old seed solution was added to the growth solution, and the mixture was left for 24 hours at ambient temperature.

\section{Preparation of surface modified AuNRs}

Si-AuNR was synthesized by adding a mixture of $10 \mathrm{mM}$ APDES and MPTMS to the prepared AuNR, stirred continuously at $800 \mathrm{rpm}$ for 12 hours. Next, ammonium hydroxide at $\mathrm{pH} 9$ was added and stirred vigorously for 1 hour. The thickness of the silica layer around Au was controlled by the amount of APDES added. The mixture was centrifuged, and the particles were washed several times with ethanol.

Particle size distributions before and after surface modification were calculated using field emission scanning electron microscopy (FE-SEM; JEOL-JSM-7500F, JEOL, Tokyo, Japan) images. Likewise, Zeta-potential measurements of the AuNRs and Si-AuNRs were taken using a Malvern ZetaSizer 3000HS instrument (Malvern Instruments, Malvern, UK).

\section{Bacterial growth kinetics}

The bacteria strains were obtained as a gift from Bong Hyun Chung's laboratory. Bacteria were cultured aerobically in LB broth and grown at $37^{\circ} \mathrm{C}$ for $4-6$ hours with continuous agitation at $200 \mathrm{rpm}$. The organisms were harvested by centrifugation at 4,000 rpm $\left(4^{\circ} \mathrm{C}\right)$ for 5 minutes, washed twice with PBS and then re-suspended in double-distilled water. The cell growth was determined by measuring optical density (OD) using spectrophotometer at every 1 hour interval with three replications.

\section{Endogenous membrane peroxidase activity}

The enzyme activities in the bacteria were assessed using TMB assay. ${ }^{31}$ Approximately $80 \mu \mathrm{L}$ of the peroxidase substrate 
was incorporated in $20 \mu \mathrm{L}$ of bacteria $\left(10^{7} / \mathrm{mL}\right)$ per well of a clear and black microtiter plates. The bacteria were incubated at $37^{\circ} \mathrm{C}$ for 30 minutes with continuous shaking at 80 rpm. After the incubation period, $50 \mu \mathrm{L}$ of the $2 \mathrm{~N} \mathrm{H}_{2} \mathrm{SO}_{4}$ was added to stop further reaction and the produced blue color was read at OD of $450 \mathrm{~nm}$ using PerkinElmer Victor 3 spectrophotometer (PerkinElmer Inc., Waltham, MA, USA). Peroxidase activity was also measured for other bacteria such as B. subtilis, S. typhi, and E. faecalis for comparing with $E$. coli $\mathrm{O} 157$.

In each bacteria sample, continuous membrane peroxidase activity toward TMB substrate was further analyzed after repeated washing. The samples were washed five times and the OD was measured at $450 \mathrm{~nm}$.

\section{Impact of nanoparticle on E. coli OI57 growth}

After reaching required confluence, bacterial cells were incubated at $37^{\circ} \mathrm{C}$ in LB broth containing different concentrations $(100-500 \mu \mathrm{g} / \mathrm{mL})$ of bare AuNRs and Si-AuNRs. After incubation, samples from each nanorod-treated bacterial strain were collected at every hour to monitor the growth of E. coli $\mathrm{O} 157$ by measuring $\mathrm{OD}$ at $600 \mathrm{~nm}$ up to 8 hours. The test was performed in triplicate.

\section{Flow cytometry analysis of nanoparticle-treated E. coli OI 57}

For flow cytometry analysis, E. coli $\mathrm{O} 157$ was grown at a density of $10^{7}$ cells $/ \mathrm{mL}$. The cells were then incubated with bare AuNRs and Si-AuNRs. The cells were harvested, washed with ice-cold PBS by centrifugation and fixed with $70 \%$ cold ethanol. Resulting cell suspension was then treated with the equal parts mixture of propidium iodide (PI) and SYTO9. The cell-lysis pattern was analyzed, and the number of live cells after nanorods treatment was evaluated using flow cytometry (BD FACSCalibur; BD Biosciences). Cell membrane of live cells is impermeable to PI because of its intact nature whereas PI leaks into dead cells with compromised membranes and produces red fluorescence. SYTO9 binds to nucleic acid and produce green fluorescence. The unique fluorescence pattern directly relates to the degree of bacterial mortality.

\section{Enzymatic activity of $E$. coli OI57 in the presence of nanoparticles}

TMB substrate $(80 \mu \mathrm{L})$ was added in the 96 -well plate with $20 \mu \mathrm{L}$ of E. coli $\mathrm{O} 157\left(10^{7} / \mathrm{mL}\right)$ per well containing AuNRs and Si-AuNRs. The treated bacterial cells were incubated at $37^{\circ} \mathrm{C}$ for 30 minutes with continuous shaking at $80 \mathrm{rpm}$ Bacteria without nanorods were kept as control. Then, $50 \mu \mathrm{L}$ of the stop solution was added to cease further reaction. OD of the nanorod-treated samples were measured at $450 \mathrm{~nm}$.

\section{Morphology analysis of E. coli OI57 by electron microscopy}

Morphology of nanorod-treated bacteria after TMB assay was analyzed and compared against control cells using FESEM. AuNRs and Si-AuNRs-treated bacteria samples were placed on small pieces of cover slips. Different nanorodstreated E. coli $\mathrm{O} 157$ were fixed using 4\% glutaraldehyde buffered with $0.2 \mathrm{M}$ sodium phosphate ( $\mathrm{pH} 7)$. The samples were dried to critical-point with $\mathrm{CO}_{2}$ and sputter coated. Then, they were analyzed under the FE-SEM.

\section{Results}

\section{Fabrication and characterization of AuNRs}

To investigate the response of nanorods on $E$. coli $\mathrm{O} 157$, we fabricated AuNRs and Si-AuNRs. The short AuNRs with $A R \approx 2.5$ were prepared by a seed-mediated growth method in a single-component surfactant (CTAB) solution. The CTAB stabilized AuNRs as shown in Figure 1A were modified with a silica layer using a sol-gel hydration and condensation method. After coating, AuNRs were purified in ethanol and finally dispersed in water without forming aggregates. When the mixture of MPTMS and APDES was used, all the AuNRs were coated by silica layer without forming Au-free silica particles (Figure 1B). In the 12-hour mediation process, the amine and mercapto functional groups were attached onto the Au surfaces. ${ }^{32}$ FE-SEM analysis clearly depicts the existence of amorphous silica layer around AuNRs to form Si-AuNRs. The average particle size distributions of AuNR were measured by averaging 100 particles of each of three batches from the FE-SEM images using ImageJ software (developed by the National Institutes of Health, Bethesda, MD, USA). The size distribution of bare AuNR was calculated to be $49.8 \times 19.5 \mathrm{~nm}$ whereas the $\mathrm{Si}$-AuNR was $71.3 \times 32.1 \mathrm{~nm}$ due to the thick silica shell around the gold core. Also, the bare AuNRs showed a zeta potential value of $+52 \mathrm{mV}$. After surface modification, the charge reversal of $-33.7 \mathrm{mV}$ was obtained for the $\mathrm{Si}-\mathrm{AuNRs}$. These high zeta potential values of both bare AuNRs and Si-AuNRs supported the good colloidal stability. Generally, the particles in suspension having a large negative/positive zeta potential will tend to repel each other, and there will be no possibility aggregation thus they are considered more 

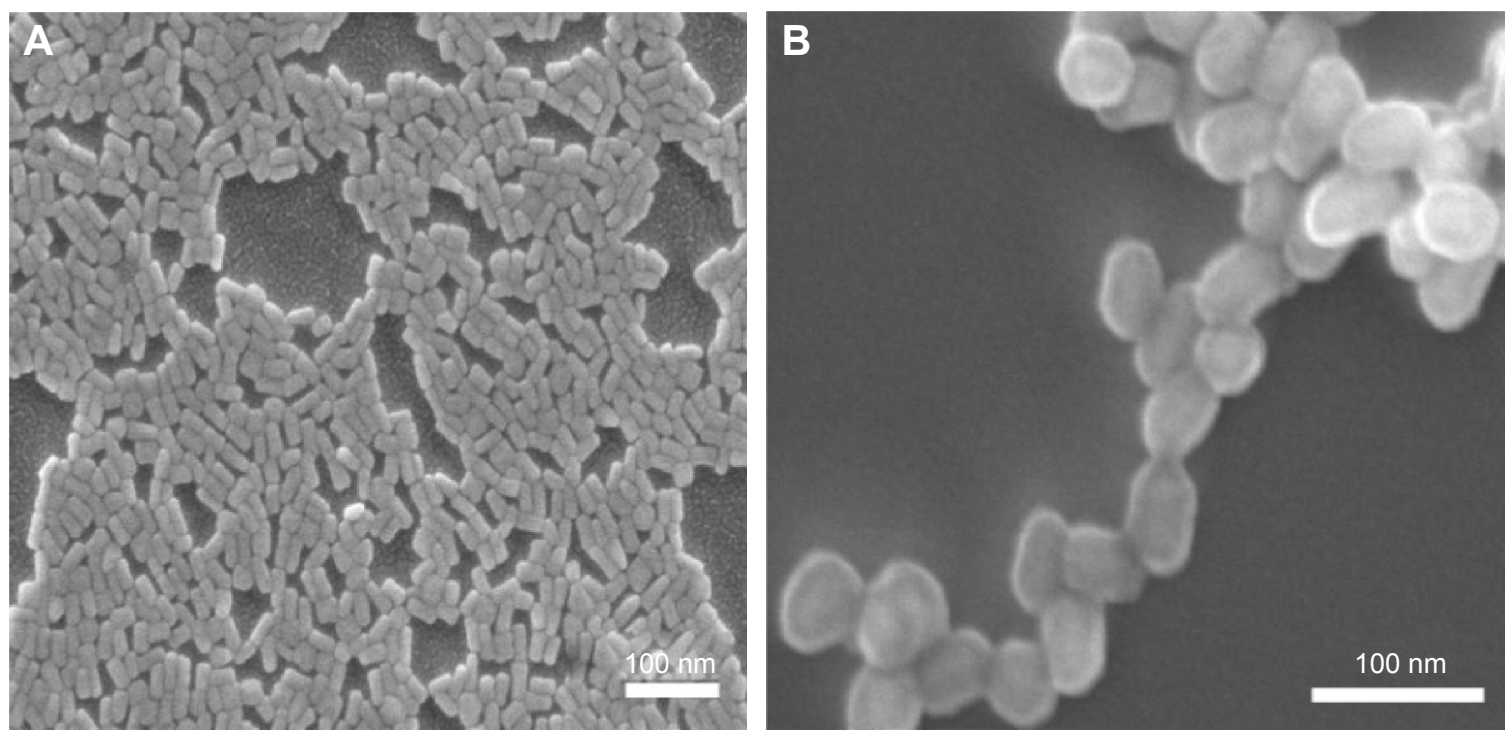

Figure I FE-SEM characterization of nanorods synthesized by modified seed-mediated method.

Notes: (A) Bare AuNRs and (B) surface-modified Si-AuNRs.

Abbreviations: FE-SEM, field emission scanning electron microscopy; AuNRs, gold nanorods; Si-AuNRs, silica-coated gold nanorods.

stable in nature. ${ }^{33,34}$ Hence, the zeta potential values confirm the formation of silica layer with better stability, which was free from aggregation.

\section{Growth kinetics of bacteria}

Comparison among the regular growth rate of different bacterial cells is shown in Figure 2. The obtained results showed that at 10 hours, B. subtilis showed higher growth, and E. coli $\mathrm{O} 157$ showed slower growth compared to E. faecalis and $S$. typhi, which showed normal growth rate at the same incubation conditions. Since all bacteria showed similar

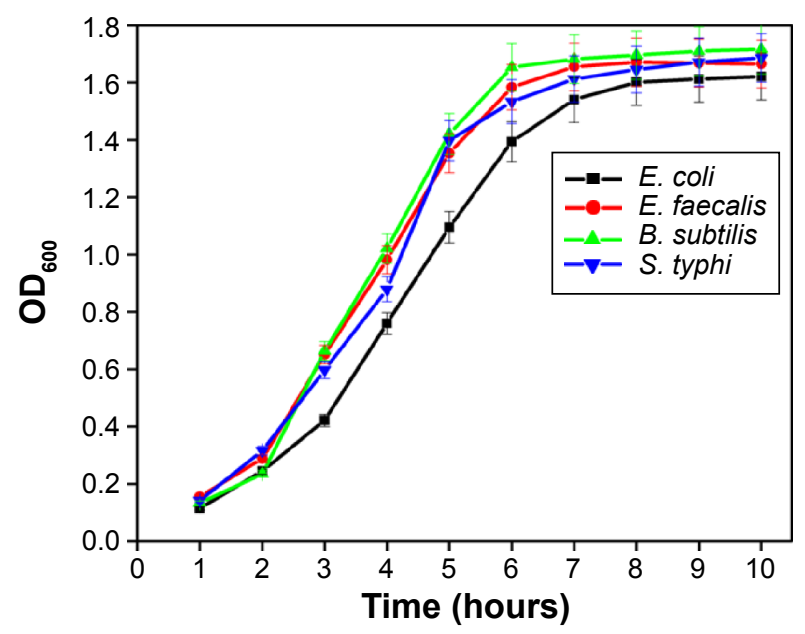

Figure 2 Bacterial dynamic growth curve of E. coli OI57, E. faecalis, B. subtilis, and S. typhi in LB medium.

Abbreviations: OD, optical density; LB, Lysogeny Broth; E. coli OI57, Escherichia coli OI 57; E. faecalis, Enterococcus faecalis; B. subtilis, Bacillus subtilis; S. typhi, Salmonella typhimurium. growth phase, these bacteria were used to analyze EMP activities.

\section{Membrane peroxidase activity}

The membrane peroxidase activity of various bacteria was evaluated with TMB substrate because it is sensitive at low hydrogen peroxide concentrations and cost effective compared to other substrates. TMB develops insoluble navy blue color (Figure $3 \mathrm{~A}$ ) after reacting with $2 \mathrm{~N} \mathrm{H}_{2} \mathrm{SO}_{4}$, which is the characteristic identification for peroxidase-labeled molecules. Hence, the results shown in Figure 3B confirmed the presence of peroxidase molecules on the surface of bacteria. When the number of bacteria increases, the enzymatic activity proportionally increased by giving enhanced signals in the assay. Compared to other three microorganisms, E. coli $\mathrm{O} 157$ showed higher enzyme activity in TMB assay. Relatively, $E$. faecalis showed significant peroxidase activity followed by B. subtilis which showed very less enzymatic activity and no enzymatic activity was observed in S. typhi.

After TMB assay for the first instance, the same bacteria samples were washed with water to remove the traces of the stop solution, and they were then analyzed again for continuous membrane peroxidase activity. Interestingly, we found that only E. coli $\mathrm{O} 157$ showed continuous enzymatic activity even after being washed more than five times with water compared with other bacteria (Figure 4). The inset picture depicts the visible color changes of the continuous enzymatic activity, where E. coli $\mathrm{O} 157$ produced yellow color (before adding stop solution) after repeated washings compared with 
A

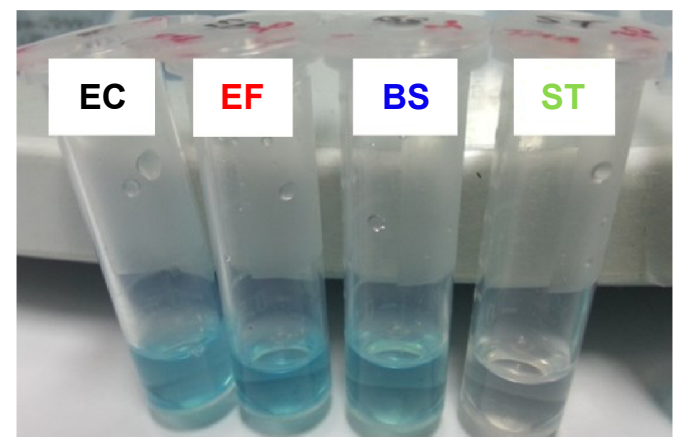

B

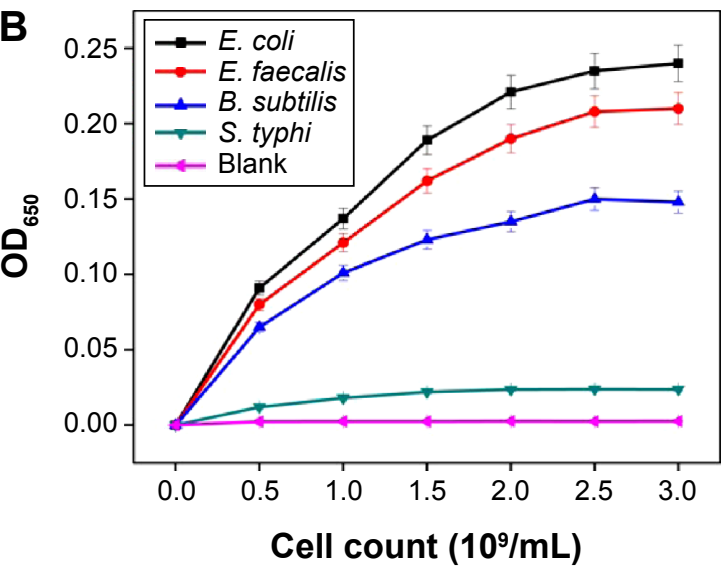

Figure 3 Endogenous membrane peroxidase activity measurement using TMB assay.

Notes: (A) Color development of bacteria samples (EC - E. coli OI57, EF - E. faecalis, BS - B. subtilis, and ST - S. typhi, respectively) in the presence of TMB substrate. (B) Optical density measurement of enzymatic active E. coli OI57, E. faecalis, B. subtilis, and S. typhi samples.

Abbreviations: OD, optical density; TMB, 3,3',5,5'-tetramethylbenzidine; E. coli OI57, Escherichia coli OI57; E. faecalis, Enterococcus faecalis; B. subtilis, Bacillus subtilis; S. typhi, Salmonella typhimurium.

other bacterial pathogens, which were colorless after washings. The possible reason can be that, E. coli $\mathrm{O} 157$ could internalize the TMB substrate thus producing repeated color. But, the exact reason for these enzymatic activity differences in bacteria are yet to be identified.

\section{Effect of the nanorods on bacterial growth}

E. coli $\mathrm{O} 157$ growth was tested to evaluate the impact of bare and surface-modified AuNRs on it, as this strain showed the

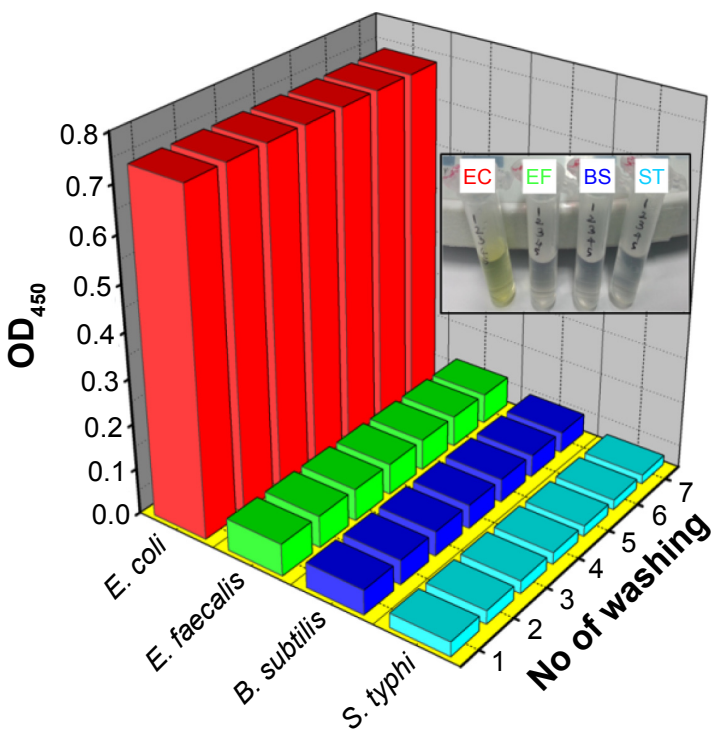

Figure 4 Repeated membrane peroxidase analysis of bacteria samples. Notes: $O D_{450}$ values of the bacteria samples after repeated washings without the addition of stop solution. Inset: Photographs of the corresponding bacterial suspensions (EC - E. coli OI57, EF - E. faecalis, BS - B. subtilis, and ST - S. typhi, respectively).

Abbreviations: OD, optical density; E. coli OI57, Escherichia coli OI57; E. faecalis, Enterococcus faecalis; B. subtilis, Bacillus subtilis; S. typhi, Salmonella typhimurium. highest enzyme activity. The comparative growth condition results between AuNRs- and Si-AuNRs-treated bacteria cells at different concentrations are shown in Figure 5. The growth rate of bacteria was calculated by using its exponential phase as described by Maurer-Jones et al. ${ }^{35}$ Obtained results (Figure 5A) clearly indicate that the AuNRs exposed cells showed more toxicity with no further cell growth at all concentrations whereas, Si-AuNRs-treated bacteria showed enhanced growth rate compared to control experiment, which resembles the nontoxic nature of the nanoparticles (Si-AuNRs). In detail, even at higher concentrations, viability was not altered for Si-AuNR-treated bacteria, but bare AuNR caused a dose-dependent decrease in the growth of O157. The growth or cell lysis was calculated by plotting the absorbance $\left(\mathrm{OD}_{600}\right)$ over time in the exponential growth phase of bacteria. It was noted that initial high absorbance values occurred from the scattering of nanoparticles in the sample (Figure 5A). Based on the followed calculations from Maurer-Jones et $\mathrm{al}^{35}$ it was apparent that the rate of growth of Si-AuNRs exposed bacteria was higher for lower concentrations, than that of control (Figure 5B). In contrast, significant decrease in growth rate was observed for all five concentrations of AuNRs-treated bacteria against control (Figure 5C).

\section{Live/dead analysis of nanoparticle treated E. coli OI57}

Flow cytometric analysis (Figure 6) was adopted to analyze the difference in bacterial viability behavior in the presence of bare AuNRs and Si-AuNRs. Here, membrane-permeating PI-mediated red fluorescence subject to dead cell staining and green fluorescence by SYTO 9 subject to a total live-cell 
A

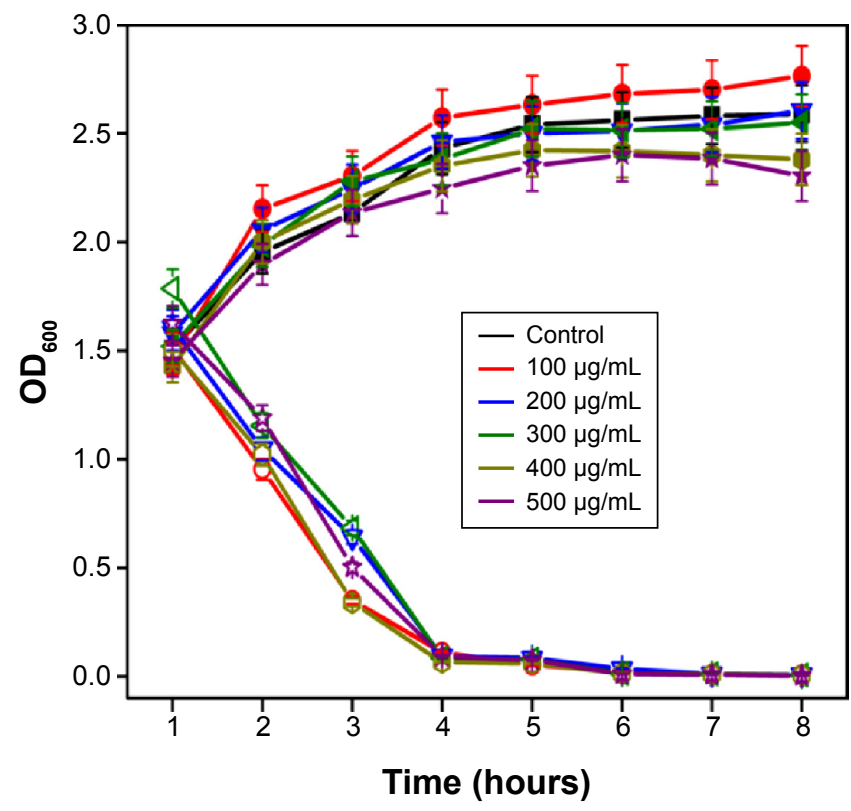

B
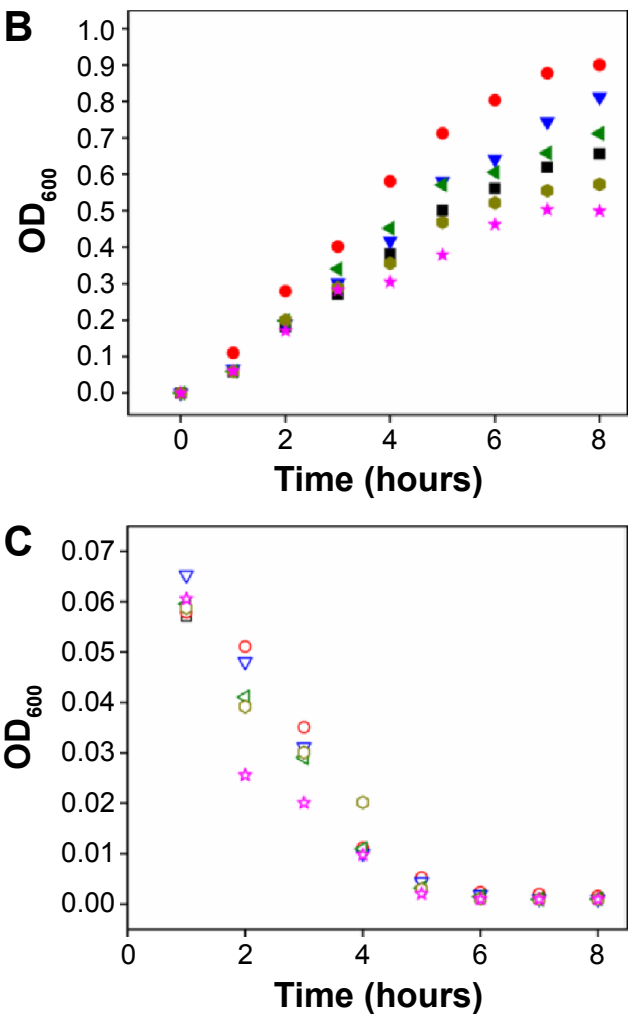

Figure 5 Growth rate of E. coli OI57 in the presence of uncoated and surface coated AuNRs.

Notes: (A) Exponential growth phase and lysis rate of bacteria in the presence of Si-AuNRs and AuNRs, respectively. (B) Bacteria growth curve values subtracted with OD at time 0 hour considered as scattering values of used Si-AuNRs. (C) Lysis rate of bacteria samples in the presence of AuNRs. Open symbols ( $\square$, $\bigcirc, \nabla, \triangleleft$, 你, $\square$ ) represent control and I00, 200, 300, 400 and $500 \mu \mathrm{g} / \mathrm{mL}$ concentrations of bare AuNRs; and closed symbols ( $\mathbf{\square}, \boldsymbol{\bullet}, \boldsymbol{\nabla}, \boldsymbol{4}, \star, \bullet)$ represent control and I00-500 $\mu \mathrm{g} / \mathrm{mL}$ concentrations of Si-AuNRs, respectively.

Abbreviations: OD, optical density; E. coli OI57, Escherichia coli OI57; AuNRs, gold nanorods; Si-AuNRs, silica-coated gold nanorods.

staining, resulted in a distinctive fluorescence pattern for the bacteria exposed to different AuNRs. The corresponding signals were denoted as PI fluorescence in FL1 channel and SYTO 9 fluorescence in FL3 channel, respectively. Figure 6A shows the flow cytometric patterns of $E$. coli O157, which was exposed to different doses of AuNRs and Si-AuNRs. Initially, the untreated control cells showed unique one population (region 1) with none or less dead cells (region 2). However, after AuNR treatment, bacteria exhibited increased fluorescence intensity in FL1 channel showing the cell lysis. The data demonstrate that when the bare AuNRs concentration was increased to $200 \mu \mathrm{g} / \mathrm{mL}$ or higher, there was an increased damage in bacteria due to injured cells followed by total cell death, which was recorded with higher fluorescence density in region 2. Thus, it exhibits the growth inhibition for the bare AuNRs-treated bacteria cells. In contrast, Si-AuNRs-treated bacteria up to $400 \mu \mathrm{g} / \mathrm{mL}$ concentration showed only single population indicating low mortality which was similar to the control that caused non-separated unique population at FL3 channel (SYTO 9 fluorescence) in region 1. At the highest concentration of Si-AuNRs $(500 \mu \mathrm{g} / \mathrm{mL})$, there was a minimal cell lysis observed with more injured cells in region 1 which was comparatively the lower cell lysis rate than bare AuNRs. Hence, with increasing dose levels, there was no specific cell lysis observed for Si-AuNRs even at higher concentrations. This indicates that the exposed Si-AuNRs were nontoxic to the bacteria. Figure 6B depicts the corresponding statistical analysis values of the flow cytometry results. Increasing the AuNRs, concentration from $100 \mu \mathrm{g} / \mathrm{mL}$ to $500 \mu \mathrm{g} / \mathrm{mL}$ resulted in a markedly higher lysis rate from approximately $98 \%$ to $2 \%$, respectively. On the other hand, increasing the concentration of Si-AuNRs did not affect the bacteria viability. More specifically, the lethal rate of bacteria at $500 \mu \mathrm{g} / \mathrm{mL}$ was only $20 \%$ with approximately $80 \%$ live bacteria. Altogether, the bare AuNRs-exposed bacteria resulted in higher cell death whereas Si-AuNRs-treated bacteria showed a higher number of live cells even at the highest concentration of Si-AuNRs. This reveals that surface-coated AuNRs can enhance the cell growth, which could be useful to detect the bacteria without lysis.

\section{Impact of the nanorods on the membrane peroxidase activity of OI57}

E. coli $\mathrm{O} 157$ in the presence of bare AuNRs and Si-AuNRs was tested in a dose- and time-dependent manner to analyze the 

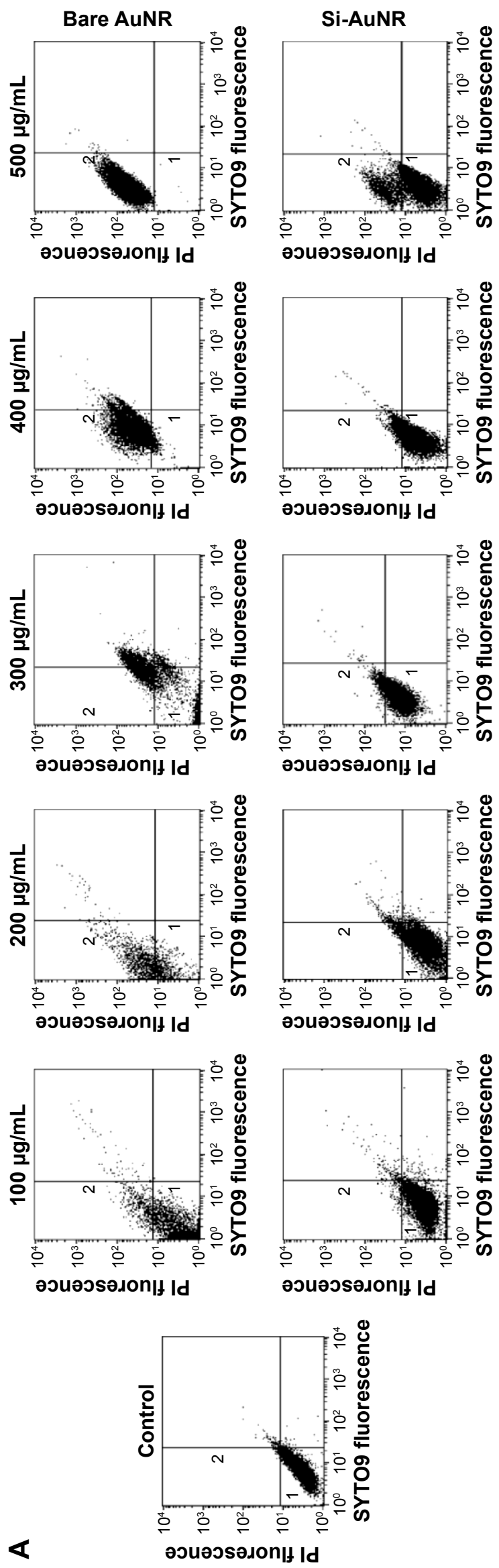

$\boldsymbol{m}$

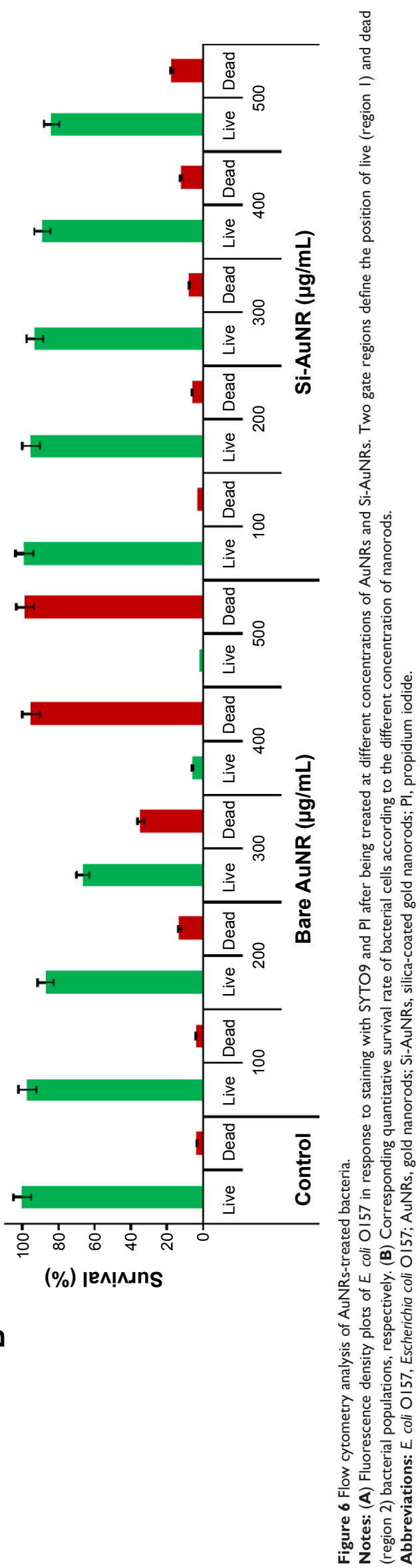




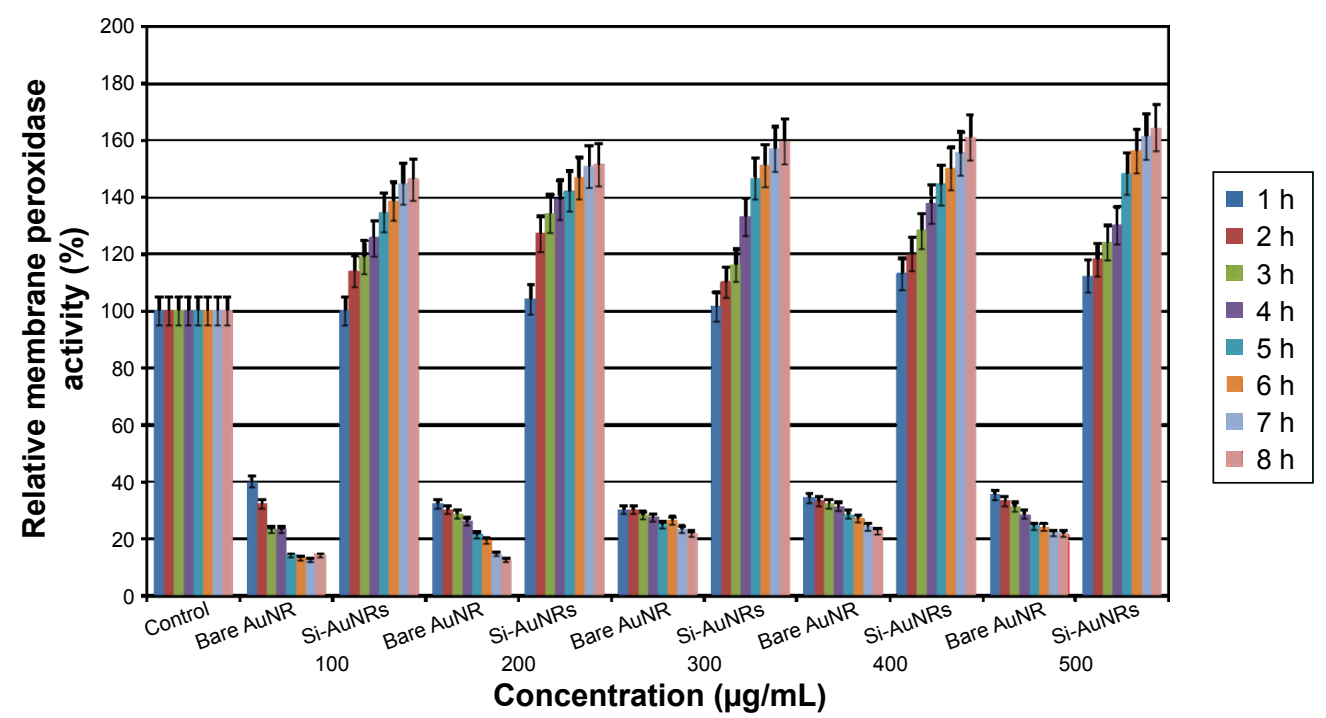

Figure 7 Specific membrane peroxidase activity of E. coli OI57 in the presence of AuNRs and Si-AuNRs compared to control cells. Abbreviations: E. coli OI57, Escherichia coli OI57; AuNRs, gold nanorods; Si-AuNRs, silica-coated gold nanorods; h, hours.

membrane peroxidase activity. Figure 7 depicts the effect of nanoparticles and alterations in the enzymatic activity of bacteria. Bare AuNRs-treated bacteria showed reduced membrane peroxidase activity with increasing time as compared to the control cells. At the starting time, the enzymatic activity was higher but when the incubation time reached 8 hours, the peroxidase activity was reduced. An opposite trend in membrane peroxidase activity has been observed for Si-AuNRs-exposed bacteria. When the concentration of Si-AuNRs increased from $100 \mu \mathrm{g} / \mathrm{mL}$ to $500 \mu \mathrm{g} / \mathrm{mL}$, the enzyme activity also increased comparatively against the control. Interestingly, the time dependency also enhanced the membrane peroxidase activity to twofold compared to the control, which could be due to the formation of new bacteria cells.

\section{Morphology of nanorods-treated E. coli OI57}

The morphological changes of the bacteria in the presence of nanorods were analyzed using FE-SEM study (Figure 8). The TMB assayed, bare AuNRs-treated bacteria showed disintegrated cell structure in Figure 8Bi compared to intact, proximally populated control cells (Figure 8Ai and Aii). More precisely, the enlarged view clearly depicts the ruptured, irrecoverable, disordered population in bare AuNRstreated bacteria cells (AuNRs as white dots; Figure 8Bii). On the other hand, Si-AuNRs-treated bacteria showed enhanced growth with the formation of new populations as shown in Figure $8 \mathrm{Ci}$. Attachment of Si-AuNRs on the surface of bacteria with enhanced formation of new colony was observed (Figure 8Cii). These observations corroborate the significant impact of the uncoated and coated nanorods on bacterial growth and enzymatic activity.

\section{Discussion}

This experiment was conducted for evaluating the impact of bare AuNRs and Si-AuNRs on growth and enzymatic activity of $E$. coli $\mathrm{O} 157$, a highly virulent bacterial strain. AuNRs were prepared by modified seed-mediated method and silica-coated method using the reaction mixture of MPTMS and APDES. Electron microscopy confirmed the formation of silica layer around each AuNR without aggregation. Both bare and surface-coated AuNRs were applied and their impacts on the bacterial growth and enzymatic activity were analyzed. Since O157 showed the highest enzymatic activity, it was selected to evaluate the different concentration $(100-500 \mu \mathrm{g} / \mathrm{mL})$ effects of bare AuNRs and Si-AuNRs. The result of cell growth revealed that bare AuNRs inhibited the growth of O157 compared to Si-AuNRs. In contrast, Si-AuNR had a positive relationship with the bacteria growth. At the starting point, the number of cells incubated was $1 \times 10^{7} / \mathrm{mL}$. After 8 hours of incubation, the number of cells in the control group increased by onefold in their log phase. Interestingly, the bacterial cells treated with surface modified-AuNRs showed increased growth rate with control. After 8 hours, cells treated with $100 \mu \mathrm{g} / \mathrm{mL}$ showed approximately threefold increase in the number of cells compared with that of the control group whereas, cells treated with the maximum $500 \mu \mathrm{g} / \mathrm{mL}$ showed a decrease in their growth at total 8 hours. This trend may be a function of nonspecific surface bonding or adsorption of broth components onto the 

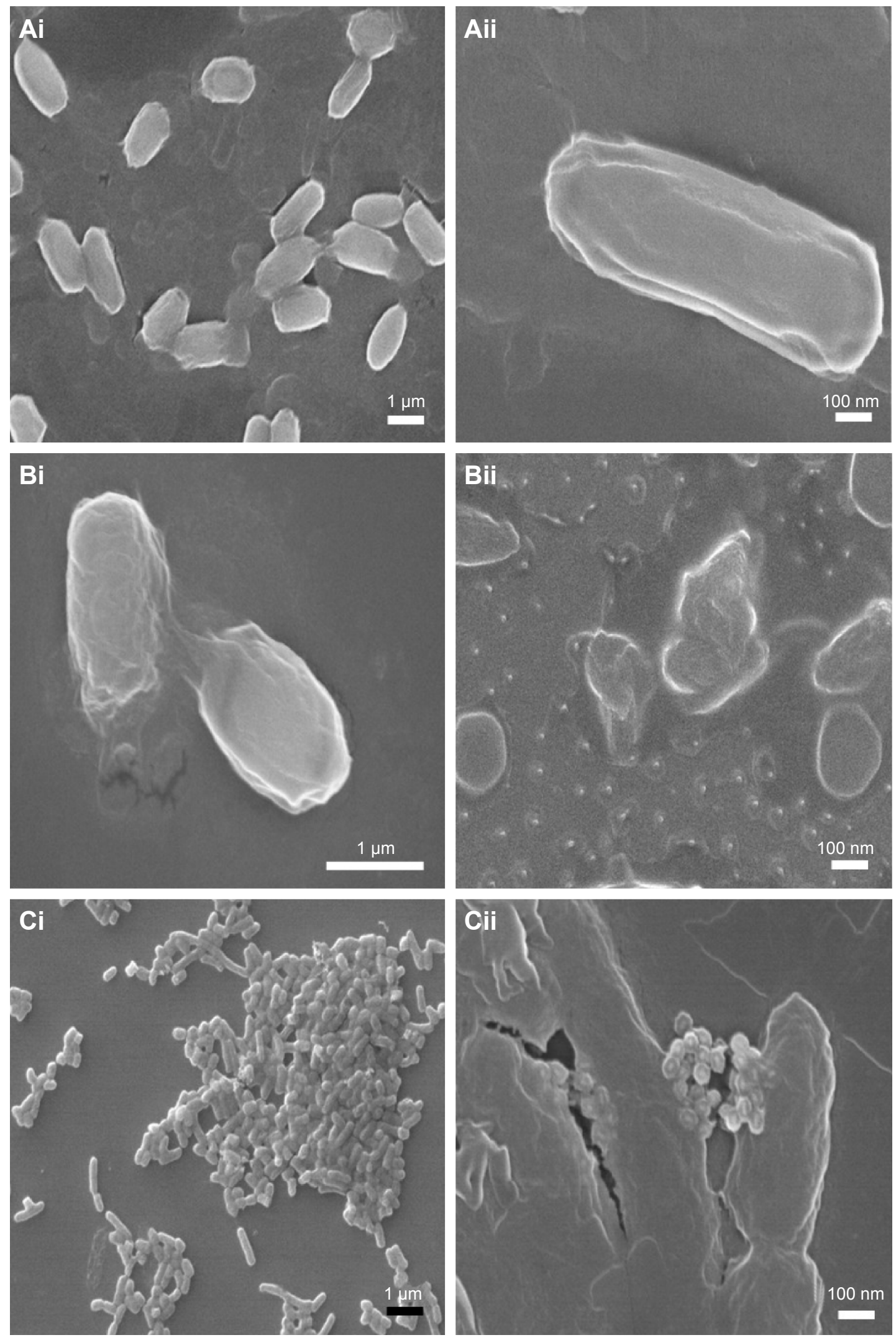

Figure 8 Morphological analyses of $E$. coli OI57 after TMB assay using FE-SEM.

Notes: Panels (Ai and $\mathbf{A i i})$ represent the untreated control bacteria and its magnified image. (Bi) AuNRs-treated bacteria, (Bii) disoriented cells after treatment. (Ci) Enhanced bacteria growth toward Si-AuNRs, (Cii) specific attachment of Si-AuNRs with E. coli cells by maintaining complete cell morphology.

Abbreviations: FE-SEM, field emission scanning electron microscopy; TMB, 3,3'5,5'-tetramethylbenzidine; E. coli OI57, Escherichia coli OI57; AuNRs, gold nanorods; Si-AuNRs, silica-coated gold nanorods. 
surface of Si-AuNRs. As described previously, three major factors are responsible for dynamic nano-bio interfaces, 1) physicochemical composition of nanoparticles, 2) modifications in the interface of nanoparticle in the surrounding medium, and 3) contact area of the nanoparticle interface with biological components. In specific, AuNRs after surface modifications may form increased interaction with biological substrates. ${ }^{36,37}$ Likewise, from our findings Si-AuNRs resulted in higher cell viability even at higher concentrations than uncoated AuNRs.

The results were further established by flow cytometric analysis. The cells treated with Si-AuNRs observed with an increased SYTO9-mediated green fluorescence intensity in a dose-dependent manner describing healthy cells, whereas PI-mediated red fluorescence was increased at FL1 channel with increasing dose of bare AuNRs, indicating a gradual shift in cell population from FL3 channel to FL1 for damaged bacteria. In contrast, PI-mediated red fluorescence increased at FL1 channel with increasing dose of bare AuNRs, indicating a gradual shift from FL3 channel to FL1. These results clearly demonstrate that the Si-AuNRs significantly maintained the bacteria alive whereas bare AuNRs were toxic to the cells and caused cell lysis. The morphological analysis also supported the viability differences of $\mathrm{O} 157$ toward bare AuNRs and Si-AuNRs.

In total, possibility of nanoparticle-mediated cell death was because of inherent toxicity produced by CTAB present in the AuNRs. The number of bare AuNRs-treated cells decreased gradually with time and nearly came to 0 after 8 hours. Although surface CTAB was removed by washing, still residual amount and desorption of CTAB might cause cell lysis. Furthermore, strong positive surface charge of AuNRs might also be associated with the decreased growth rate in bacteria.

In contrast, Si-AuNRs favored bacterial growth. This can be hypothesized by the hydrophilic and nontoxic nature of silica. Delving further into it, silica layer can provide many advantages over free cell growth. Previous reports demonstrated that silica matrices facilitated $E$. coli growth as it increased metabolic activity and plasmid stability, and provided a nontoxic environment. ${ }^{38-40}$ It is supported by the results we obtained by evaluating the enzymatic activity of the bacteria. Among the four different bacteria, E. coli O157 demonstrated the highest level of membrane peroxidase activity which is inconsistent with previous report. ${ }^{31}$ When we incorporated nanorods in the media, peroxidase activity greatly varied depending on the types of nanorods. Enzymatic activity was found quite low in case of AuNRs-treated bacteria. This can be correlated with the growth inhibition of
O157 by AuNRs. Decreased bacterial growth resulted in a decrease in the endogenous membrane peroxidase activity. Also, TMB might be repulsed by the positive charge of AuNRs as TMB tends to bind to the negatively charged particles because of its net positive charge resulting from amine groups. On the other hand, Si-AuNRs significantly increased the membrane peroxidase activity in dose- and time-dependent manner. It also increased in dose- and timedependent manner. After 8 hours incubation, approximately $10 \%-15 \%$ increase in enzyme activity was observed at the dose $500 \mu \mathrm{g} / \mathrm{mL}$ compared with that of control. At dose $100 \mu \mathrm{g} / \mathrm{mL}$, a $25 \%$ increase was observed after 8 hours than the activity at 1 hour. Similarly, the other concentrations of SiAuNRs showed approximately 40\%-50\% increase in enzyme activity at 8 hours compared with that at 1 hour. Since, our method shows better results, the membrane peroxidase activity of the bacteria could be enhanced with surface-modified AuNRs after directly using with the substrate TMB. Here, the main difference is silica-coated AuNRs showed enhanced visible color change compared with only bacteria with TMB. Moreover, TMB tends to be attracted more to the negatively charged silica-coated AuNRs via electrostatic attraction, and favorable conformational changes were reported once the enzyme was bound to nanoparticles, causing increased TMB signals. Also, silica-coated AuNR acts as an artificial enzyme along with natural membrane peroxidase present in the bacteria, which increased the sensitivity of detection with TMB thus resulting in enhanced TMB signals in our methods. In addition, silica covering could provide large specific surface area for more TMB loading by the interaction with protein molecules present in the bacteria. ${ }^{28,38}$ But, Gao et al presented an interesting report for the high TMB signals. ${ }^{41}$ Increase in enzyme concentration or $\mathrm{H}_{2} \mathrm{O}_{2}$ with TMB substrate creates multiple nucleation centers to form different self-assembled nanostructures by producing different colors due to charge-transfer complex. ${ }^{42}$ In corroboration with our results, the more viable Si-AuNRs-treated O157 could form high enzyme concentration thus producing large signals compared to control bacteria after reacting with TMB substrate. This capability of nanoparticle-mediated enzymatic response may also create new opportunities in the preparation of smart-sensors and as a powerful bio-analytical tool.

The results of these experiments indicate that Si-AuNRs can be used as bacterial growth enhancers for a rapid detection. They can also be used for increasing the sensitivity of TMB assay for the detection of E. coli O157. Si-AuNRs may also be potentially applied as biocatalyst and for metabolite production, and for constructing biosensors. 


\section{Conclusion}

Here, we have demonstrated the efficacy of bare and surfacemodified AuNRs on highly pathogenic bacterial strains for their growth and corresponding enzyme activity. Bare AuNRs inhibited the growth and decreased the enzyme activity whereas surface-modified AuNRs favored excellent bacterial growth, higher metabolic activity and enhanced membrane peroxidase signal. The effects were observed in a dose- and time-dependent manner. The results suggest that silica coating on AuNRs makes them promising agents for potential bacterial growth and increasing detection sensitivity for other applications.

Since, nanoparticle interactions toward bacteria are relatively new field, this study presents an important approach to analyzing their enzymatic activity. That is, a clear understanding of the bare and surface-coated AuNRs, impact on bacteria is gained, and this explores beneficial information to make safer nanoparticles without toxicity.

\section{Acknowledgment}

This work was supported by the grants of National Research Foundation of Korea (NRF), funded by the South Korean government (MEST) (2012R1A2A2A03046819) and (2013R1A1A2005329).

\section{Disclosure}

The authors report no conflicts of interest in this work.

\section{References}

1. Newell DG, Koopmans M, Verhoef L, et al. Food-borne diseases - the challenges of 20 years ago still persist while new ones continue to emerge. Int J Food Microbiol. 2010;139:S3-S15.

2. World Health Organization. EHEC Outbreak: Increase in Cases in Germany. World Health Organization; 2011. Available from: http://www. who.int/csr/don/2011_06_02/en/index.html. Accessed June 28, 2015.

3. Zhang Y, Wang G, Wu Y, Zhao H, Zhang Y, Sun Z. PCR-DGGE analysis of earthworm gut bacteria diversity in stress of Escherichia coli $\mathrm{O} 157: \mathrm{H} 7$. Adv Biosci Biotechnol. 2013;4:437-441.

4. Turner M. German E. coli outbreak caused by previously unknown strain Nature News \& Comment, 2011. Available from: http://www.nature.com/ news/2011/110602/full/news.2011.345.html. Accessed June 28, 2015.

5. Walterspiel JN, Ashkenazi S, Morrow AL, Cleary TG. Effect of subinhibitory concentrations of antibiotics on extracellular Shiga-like toxin I. Infection. 1992;20(1):25-29.

6. Hinz B, Cheremina O, Brune K. Acetaminophen (paracetamol) is a selective cyclooxygenase-2 inhibitor in man. FASEB J. 2008;22: 383-390.

7. Farr SP, Kogoma T. Oxidative stress responses in Escherichia coli and Salmonella typhimurium. Microbiol Rev. 1991;55:561-585.

8. Brichta-Harhay DM, Arthur TM, Bosilevac JM, Guerini MN, Kalchayanand N, Koohmaraie M. Enumeration of Salmonella and Escherichia coli O157:H7 in ground beef, cattle carcass, hide and faecal samples using direct plating methods. J Appl Microbiol. 2007;103(5): $1657-1668$.

9. Bai Y, Huang WC, Yang ST. Enzyme-linked immunosorbent assay of Escherichia coli $\mathrm{O} 157: \mathrm{H} 7$ in surface enhanced poly(methyl methacrylate) microchannels. Biotechnol Bioeng. 2007;98(2):328-339.
10. Simpson JM, Lim DV. Rapid PCR confirmation of E. coli O157:H7 after evanescent wave fiber optic biosensor detection. Biosens Bioelectron. 2005;21(6):881-887.

11. Barreiros dos Santos M, Agusil JP, Prieto-Simón B, Sporer C, Teixeira V, Samitier J. Highly sensitive detection of pathogen Escherichia coli $\mathrm{O} 157: \mathrm{H} 7$ by electrochemical impedance spectroscopy. Biosens Bioelectron. 2013;45:174-180.

12. Yacoby I, Benhar I. Antibacterial nanomedicine. Nanomedicine. 2008; 3(3):329-341.

13. Rao JH. Shedding light on tumors using nanoparticles. ACS Nano. 2008; 2(10):1984-1986.

14. Amstad E, Textor M, Reimhult E. Stabilization and functionalization of iron oxide nanoparticles for biomedical applications. Nanoscale. 2011; 3(7):2819-2843

15. Kawano T, Niidome Y, Mori T, Katayama Y, Niidome T. PNIPAM gel-coated gold nanorods for targeted delivery responding to a nearinfrared laser. Bioconjug Chem. 2009;20(2):209-212.

16. Chen CC, Lin YP, Wang CW, et al. DNA-gold nanorod conjugates for remote control of localized gene expression by near infrared irradiation. $J$ Am Chem Soc. 2006;128(11):3709-3715.

17. Su H, Zhao H, Qiao F, Chen L, Duan R, Ai S. Colorimetric detection of Escherichia coli O157:H7 using functionalized Au@Pt nanoparticles as peroxidase mimetics. Analyst. 2013;138(10):3026-3031.

18. Dussert AS, Gooris E, Hemmerle J. Characterization of the mineral content of a physical sunscreen emulsion and its distribution onto human stratum corneum. Int J Cosmet Sci. 1997;19(3):119-129.

19. He W, Liu Y, Yuan J, et al. Au@Pt nanostructures as oxidase and peroxidase mimetics for use in immunoassays. Biomaterials. 2011;32(4): $1139-1147$.

20. Liu J, Hu X, Hou S, et al. Au@Pt core/shell nanorods with peroxidaseand ascorbate oxidase-like activities for improved detection of glucose. Sens Actuators B Chem. 2012;166:708-714.

21. Asati A, Santra S, Kaittanis C, Nath S, Perez JM. Oxidase-like activity of polymer-coated cerium oxide nanoparticles. Angew Chem Int Ed Engl. 2009;48(13):2308-2312.

22. Zhang L, Laug L, Münchgesang W, et al. Reducing stress on cells with apoferritin-encapsulated platinum nanoparticles. Nano Lett. 2010; 10(1):219-223.

23. Shi W, Wang Q, Long Y, et al. Carbon nanodots as peroxidase mimetics and their applications to glucose detection. Chem Commun (Camb). 2011;47(23):6695-6697.

24. Kim MI, Shim J, Li T, Lee J, Park HG. Fabrication of nanoporous nanocomposites entrapping Fe3O4 magnetic nanoparticles and oxidases for colorimetric biosensing. Chemistry. 2011;17(38):10700-10707.

25. Thanh NTK, Green LAW. Functionalisation of nanoparticles for biomedical applications. Nano Today. 2010;5(13):213-230.

26. Giljohann DA, Seferos DS, Daniel WL, Massich MD, Patel PC, Mirkin CA. Gold nanoparticles for biology and medicine. Angew Chem Int Ed. 2010;49(19):3280-3294.

27. Kim CB, Yi DK, Kim PS, Lee W, Kim MJ. Rapid photothermal lysis of the pathogenic bacteria, Escherichia coli using synthesis of gold nanorods. J Nanosci Nanotechnol. 2009;9(5):2841-2845.

28. Zhao Y, Tian Y, Cui Y, Liu W, Ma W, Jiang X. Small molecule-capped gold nanoparticles as potent antibacterial agents that target Gram-negative bacteria. J Am Chem Soc. 2010;132(35):12349-12356.

29. Ma W, Cui Y, Zhao Y, et al. Progress of antibacterial mechanisms study on nanoparticles. Acta Biophys Sin. 2010;26(8):638-648.

30. Zhu Y, Ramasamy M, Yi DK. Antibacterial activity of ordered gold nanorod arrays. ACS Appl Mater \& Inter. 2014;6:15078-15085.

31. Shim KH, Kang M, Kim MG, Chung BH, An SSA. Detection of E. coli O157:H7 Using Its Endogenous Active Membrane Peroxidase. Toxicol Environ Health Sci. 2011;3(2):80-85.

32. Ramasamy M, Lee SS, Yi DK, Kim K. Magnetic, optical gold nanorods for recyclable photothermal ablation of bacteria. J Mater Chem B. 2014; 2(8):981-988.

33. Zeta potential in 30 minutes. Technical note. Available from: www. malvern.co.uk. Accessed June 28, 2015. 
34. American Society for Testing and Materials. Zeta Potential of Colloids in Water and Waste Water. ASTM Standard D 4187-82. West Conshohocken (PA): American Society for Testing and Materials; 1985.

35. Maurer-Jones MA, Gunsolus IL, Meyer BM, Christenson CJ,

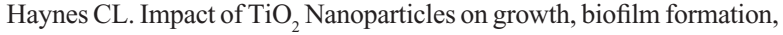
and flavin secretion in Shewanella oneidensis. Anal Chem. 2013;85(12): 5810-5818.

36. Das M, Yi DK, An SSA. Analyses of protein corona on bare and silicacoated gold nanorods against four mammalian cells. Int J Nanomed. 2015;10:1521-1545.

37. Nel AE, Mädler L, Velegol D, et al. Understanding biophysicochemical interactions at the nano-bio interface. Nat Mater. 2009;8(7):543-557.

38. Williams DN, Ehrman SH, Holoman TRP. Evaluation of the microbial growth response to inorganic nanoparticles. $J$ Nanobiotechnol. 2006;4(1):3
39. Alvarez GS, Foglia ML, Copello GJ, Desimone MF, Diaz LE. Effect of various parameters on viability and growth of bacteria immobilized in sol-gel-derived silica matrices. Appl Microbiol Biotechnol. 2009;82(4): 639-646.

40. Liu Y, Wang C, Cai N, Long S, Yu F. Negatively charged gold nanoparticles as an intrinsic peroxidase mimic and their applications in the oxidation of dopamine. J Mater Sci. 2014;49:7143-7150.

41. Gao L, Wu J, Gao D. Enzyme-controlled self-assembly and transformation of nanostructures in a tetramethylbenzidine/horseradish peroxidase/ H2O2 system. ACS Nano. 2011;5(8):6736-6742.

42. Maji SK, Mandal AK, Nguyen KT, Borah P, Zhao Y. Cancer cell detection and therapeutics using peroxidase-active nanohybrid of gold nanoparticle-loaded mesoporous silica-coated graphene. ACS Appl Mate Inter. 2015;7(18):9807-9816.

\section{Publish your work in this journal}

The International Journal of Nanomedicine is an international, peerreviewed journal focusing on the application of nanotechnology in diagnostics, therapeutics, and drug delivery systems throughout the biomedical field. This journal is indexed on PubMed Central, MedLine, CAS, SciSearch $\AA$, Current Contents ${ }^{\circledR} /$ Clinical Medicine,
Journal Citation Reports/Science Edition, EMBase, Scopus and the Elsevier Bibliographic databases. The manuscript management system is completely online and includes a very quick and fair peer-review system, which is all easy to use. Visit http://www.dovepress.com/ testimonials.php to read real quotes from published authors. 